\title{
IMPACT OF INDIGENOUSLY PREPARED THERAPEUTIC FOOD FOR CHILDREN WITH ACUTE MALNUTRITION AT NUTRITIONAL REHABILITATION CENTER
}

\author{
Joshi $P^{1^{*}}$, Yadav $J N^{2}$, Gautam $R^{3}$
}

\section{Affiliation}

1. Senior Consultant, Department of Paediatrics, Rapti Sub-Regional Hospital, Nepal

2. Consultant Physician, Department of Medicine, Rapti SubRegional Hospital, Nepal

3. Medical officer, Department of Paediatrics, Rapti Sub-Regional Hospital, Nepal

\section{ARTICLE INFO}

Received : 27 August, 2019

Accepted : 20 February, 2020

Published : 3o June, 2020

(C) Authors retain copyright and grant the journal right of first publication with the work simultaneously licensed under Creative Commons Attribution License CC - BY 4.0 that allows others to share the work with an acknowledgment of the work's authorship and initial publication in this journal.

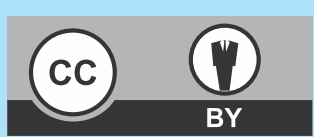

ORA 151

DOI: https://doi.org/10.3126/bjhs.v5i1.29604

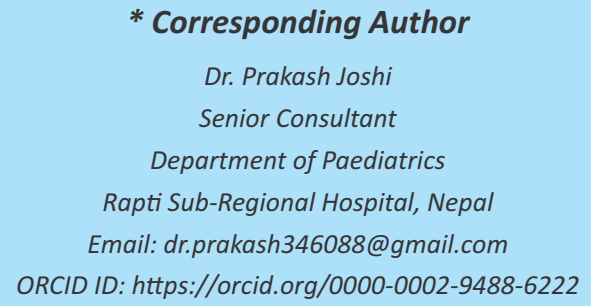

\section{Citation}

Joshi P, Yadav JN, Gautam R. Impact of Indigenously Prepared Therapeutic Food for Children with Acute Malnutrition at Nutritional Rehabilitation Center. BJHS 2020;5(1)11: 891-896.

\section{ABSTRACT}

\section{Introduction}

Malnutrition remains unacceptably high across the world especially in developing countries. ${ }^{1}$ Malnutrition not only impairs physical and mental growth of child but also increases morbidity and mortality.

\section{Objective}

To find the incidence and type of acute malnutrition and their outcome in nutrition rehabilitation center.

\section{Methodology}

This is a descriptive cross sectional study conducted at nutrition rehabilitation center of Rapti Sub-Regional Hospital (RSRH). Children between 6 to 59 months of age with severe and moderate acute malnutrition (SAM and MAM) and admitted from July 2017 to June 2018 were enrolled. Age, sex, length/height, weight, weight gain, duration of stay, $\mathrm{Z}$ score of weight for length/height (WLZ/WHZ), weight for age (WAZ) and Height for age (HAZ) were recorded. Outcome were recorded as cured, recovered, defaulted, primary failure and referred. Data entered in excel and analysis was performed by using SPSS 20. Results were expressed as number, proportion, and average.

\section{Results}

Among 105 patients admitted, 90 (85.71\%) were below the age of 24 months with mean age of study population being 16.82 months and male female ratio of 1.14:1.Proportion of children with SAM and MAM was 59(56.19\%) and 46 (47.61\%) respectively. Among 75(71.42\%) stunted children, $51(68 \%)$ were severely stunted. Among the study populations cure rate was $30.47 \%(32)$, recovery rate $24.76 \%$ (26). Defaulter rate was $87.6 \%$ (8) and primary failure were $18.09 \%$ (19). Referred were 2(1.9\%). Average weight gain was $6.56 \mathrm{mg} / \mathrm{kg} /$ day. Average duration of stay was 21.83 days.

\section{Conclusions}

Locally prepared therapeutic dietis an easy and cheapest way to combat malnutrition. Services atnutrition rehabilitation center needs to be integrated with the community-based therapeutic care to sustain the achievement and prevent relapse.

\section{KEYWORDS}

Child, malnutrition, morbidity, weight gain. 


\section{INTRODUCTION}

Malnutrition is a major public health problem throughout the developing world contributing around $50 \%$ of the $10-11$ million annual deaths in under five children. ${ }^{2}$ Globally, around 150.8 million children under five years of age are stunted (short for their age) and 50.5 million children under five are wasted (thin for their height) respectively with nearly 17 million of them being severely wasted. ${ }^{1,3}$ Around 3.62\% (15.95 million) of them are both stunted and wasted. ${ }^{1}$ More than half of the world's wasted children are living in South Asia. ${ }^{3}$ To our concern, Nepal also shares this burden of malnutrition with its $36 \%$ of under five children being stunted, $10 \%$ wasted, and $27 \%$ underweight (thin for their age). ${ }^{4}$

According to WHO, severe Acute Malnutrition (SAM) defined as having a weight-for-height $z$ score $(\mathrm{WHZ})<-3$, increases mortality, morbidity, impairs physical and mental growth of child. The risk is lower in children with Moderate Acute Malnutrition (MAM) defined as WHZ between -2 and 3 SD. ${ }^{5}$ Overall risk of death among children with SAM is 9 times more that of well-nourished children which is 3 -fold higher in children with MAM ${ }^{5,6} \mathrm{~A}$ child who is both wasted and stunted is 12 times more likely to die than a normal child? Malnourished children requiring immediate attention with proper nutritional therapeutic care are admitted at Nutrition Rehabilitation Homes/Centers (NRHs/NRCs) running throughout the country with support of Nepal Youth Opportunity Foundation (NYOF). ${ }^{8}$

There is paucity of literature regarding incidence of malnourished children and outcome of nutritional rehabilitation in a hospital based setting, particularly in western Nepal, hence this study was conducted with the objective to evaluate the incidence and type of malnutrition as well as the effectiveness of nutrition rehabilitation center in providing therapeutic care with standard WHO protocols and locally prepared therapeutic diet for children with malnutrition in Hospital based nutrition rehabilitation centers.

\section{METHODOLOGY}

This cross sectional descriptive hospital-based study was conducted retrospectively at the NRH of Rapti Sub-Regional Hospital in Ghorahi Sub-Metropolitian City of Dang District. This hospital now has been taken over by Rapti Academy of Health Sciences as its teaching hospital. Data of all the malnourished children between 6 to 59 months of age, admitted in rehabilitation center from July 2017 to June 2018 were reviewed. Ethical clearance and approval for the study was obtained from the Medical Superitendent.

This nutrition rehabilitation center was established as a unit of Rapti Sub-Regional Hospital in collaboration with NYOF aiming to serve the malnourished children of this region. Though it was started targeting only children with SAM, considering the high public demand and geographical distance they come from, we used to admit cases with MAM also. Nurses, dieticians and the cooks were specially trained in identifying children with MAM and SAM and nutritional rehabilitation protocols. Children admitted at rehabilitation center were nutritionally rehabilitated using therapeutic feeding diets (F-75 and F-100) prepared using locally available food-stuff. The mothers of the children are made to stay at the centers where training on composition and preparation of the therapeutic diets from local resources, as well as counseling sessions focusing on health and nutrition aspects are conducted for them. Children were received directly into inpatient care of nutrition rehabilitation center via identification at the outpatient department of the hospital on the basis of WHO criteria of WHZ score or by referral from the FCHV or other community health workers. These children were closely monitored for $24 \mathrm{hr}$ dietary intake, weight gain $(\mathrm{gm} / \mathrm{kg} / \mathrm{d})$, any fresh signs and symptoms for medical comorbidities and were screened if signs suggestive of any infection were seen. Patient management is based on the global guidelines by WHO and UNICEF which have been adapted, where necessary, to the context of Nepal as inlntegrated Management of Acute Malnutrition (IMAM) Protocols Nepal.

Children were discharged from the rehabilitation center when they met following criteria (i) child had attained the target weight of $\mathrm{WHZ} \geq-1$. (ii) was active and alert (iii) had absence of complications or evidence of any infection. (iv) Child was tolerating home based feeds. (v) Primary caretaker was confident about taking care of the child.

The study population included malnourished children, both SAM and MAM, between 6-59 months of age, admitted and treated at nutrition rehabilitation center of Rapti SubRegional Hospital. Children below 6 months were excluded for being associated with some congenital disorder. Records books were manually reviewed and variables recorded wereage in completed months, gender, anthropometry (length/ height and weight) during admission, discharging weight and outcome of the rehabilitation course. Weight has been taken as the main anthropometric as an improvement in weight of severe malnourished children has the most significant effect in reducing the mortality among them. ${ }^{9} \mathrm{Z}$ score for WFL/H, WFA, HFA, according to WHO growth standard was calculated. Weight gain during stay was calculated as. ${ }^{10}$

Weight gain in $\mathrm{g} / \mathrm{kg} /$ day $=\frac{(\mathrm{W} 2-\mathrm{W} 1) \times 1000}{(\mathrm{~W} 1 \times \text { number of days from W1 to } \mathrm{W} 2)}$

where: $W 1=$ initial or lowest weight in $\mathrm{kg}$; W2 = weight in $\mathrm{kg}$ on the day of calculation.

Duration of stay was calculated from date of admission and discharge. Variables extracted were entered into a structured Microsoft excel template and analysis was performed by using SPSS version 20 and the results were expressed as number, proportion, mean and average.

Outcome was defined as cured, recovered, defaulter, primary failure and referred. Outcome were compared with internationally accepted Sphere standards, that were laid down initially under the Sphere project in 1998 and later revised and represent minimum international standards in various core domains to be attained in humanitarian response. $^{11}$ 
Operational definitions: ${ }^{5,12-14}$,

Cured -Those who attained the target of achieving the WHZ score of-1SD.

Recovered - A child who has achieved WLZ or WHZ > - 2 but has not achieved target weight by the time they left the rehabilitation center.

Slow responder: Those who gained weight at desired rate of $5 \mathrm{gm} / \mathrm{kg} /$ day or more but not reached $\mathrm{WHZ}>-2$. Majority of them were those who took early discharge on request.

Primary failure- Those who didn't gain weight at the rate of 5 $\mathrm{gm} / \mathrm{kg} /$ day despite appropriate nutritional support by day 10 of stay.

Default- Those who left the center before actual treatment or dietary support was started that is before 7 days of admission.

Rate of each outcome is calculated as

$$
\text { Outcome Rate }=\quad \frac{\text { Number of subjects with particular outcome X100 }}{\text { Total number of study subject }}
$$

For example, Cure Rate is calculated as

$$
\text { Cure Rate }=\frac{\text { Number of cured subjects } X 100}{\text { Total number of study subject }}
$$

\section{RESULTS}

During the study period 105 children were admitted out of which, children with SAM and MAM were 59 (56.19\%) and 46(43.81\%) respectively. Around 75 (71.42\%) children in study group were stunted of which $51(68 \%)$ were severely stunted. Severe stunting was seen among 31 (52.54\%) and $20(43.47 \%)$ children with SAM and MAM respectively. Among SAM male (67.79\%) predominates over female with male female ratio was [2.1:1] whereas among MAM females were predominantly affected, with male female ratio of [0.53:1]. [Table.1]
Among the admitted subjects, 56 (53.33\%) were male and 49 (46.66\%) were female having male female ratio M:F of 1.14:1. Infant constitute 29 (27.61\%). Majority ( $n=61$; $58.09 \%$ ) of the patients were between the age group 12 and 23 months thus accounting 90 (85.71\%) children below 2 years of age. The mean age of study population was $16.83 \pm 9$ months.

Among the total study subjects $32(30.47 \%)$ children were cured, including, 10(31.32\%) severely malnourished and $22(68.75 \%)$ moderately malnourished. Recovery was seen in $26(24.76 \%)$ children, out of which 15 (57.69\%) and 11 (42.30\%) children were from SAM and MAM group respectively. Cure rate was higher in female 17 (53.12\%) than males 15 (46.87\%) whereas recovery rate was better among male $15(57.69 \%)$ than females $11(42.30 \%)$ children. Around 19 (18.09\%) children were slow responder and 8 (7.6\%) children defaulted from the program. Default rate was equal among male and females. Primary failure was seen in $19(18.09 \%)$ children, which includes $12(63.15 \%)$ from SAM and $7(36.84 \%)$ from MAM group. Two cases $(1.9 \%)$ with MAM were referred due to requirement of Pediatric Intensive Care Unit. There was no mortality in rehabilitation center.

Average weight gain among total study population was 6.56 $\pm 3.57 \mathrm{gm} / \mathrm{kg} /$ day with $6.90 \pm 3.98 \mathrm{gm} / \mathrm{kg} /$ day among boys and $6.17 \pm 3.03 \mathrm{gm} / \mathrm{kg} /$ day among girls. Weight gain was poor $(<5$ $\mathrm{gm} / \mathrm{kg} /$ day), moderate (5-10 gm/kg/day) and good (>10 $\mathrm{gm} / \mathrm{kg} /$ day) among 27(25.7\%), 63 (60\%) and 14 (13.33\%) admitted children respectively. Categories and comparison of weight gain among children with SAM and MAM was as shown in Table 2.

Mean weight at admission $6.42 \pm 1.21 \mathrm{~kg}$ and discharge 7.28 $\pm 1.40 \mathrm{~kg}$. A statistically significant difference was observed between the mean weight at discharge and the mean weight at admission for the study group. Average duration of stay was $21.84 \pm 10.11$ days for the entire study subject.

Table:1 Age and Sex Distribution of the patients.

\begin{tabular}{|c|c|c|c|c|c|c|c|}
\hline $\begin{array}{c}\text { Age } \\
\text { (months) }\end{array}$ & $\begin{array}{c}\text { Male } \\
(\%)\end{array}$ & $\begin{array}{c}\text { Female } \\
(\%)\end{array}$ & $\begin{array}{c}\text { Total (Ts) } \\
\mathbf{N}(\%)\end{array}$ & $\begin{array}{c}\text { Male } \\
(\%)\end{array}$ & $\begin{array}{c}\text { Female } \\
(\%)\end{array}$ & $\begin{array}{c}\text { Total (Tm) } \\
\mathbf{N}(\%)\end{array}$ & $\begin{array}{c}\text { Grand total } \\
\text { (Ts+Tm) } \\
\mathbf{N}(\%)\end{array}$ \\
\hline $6-11$ & 11 & 9 & 20 & 2 & 7 & 9 & $29(27.61 \%)$ \\
\hline $12-23$ & 23 & 7 & 30 & 13 & 18 & 31 & $61(58.09 \%)$ \\
\hline$>24$ & 6 & 3 & 9 & 1 & 5 & 6 & $15(14.28 \%)$ \\
\hline Total & 40 & 19 & 59 & 16 & 30 & 46 & 105 \\
& $(38.09 \%)$ & $(18.09 \%)$ & $(56.19 \%)$ & $(15.23 \%)$ & $(28.57 \%)$ & $(43.80 \%)$ & $(100 \%)$ \\
\hline
\end{tabular}


Table:2 Comparison of performance of total children, SAM and MAM

\begin{tabular}{|l|c|c|c|}
\hline \multicolumn{2}{|c|}{ Children with } & \\
\hline Variables & SAM (\%) & MAM (\%) & Total (\%) \\
\hline Mean wt gain (gm/kg/D) & & & \\
\hline Boys & 7.18 & 6.21 & 6.91 \\
\hline Girls & 6.58 & 5.91 & 6.17 \\
\hline Weight gain >8gm/kg/D) & $14(13.33)$ & $2(1.9)$ & $16(15.23)$ \\
\hline Mean change in wt(kg) & & & \\
\hline Discharge vs Admission & $7.00-6.07$ & $7.63-7.01$ & $7.28-6.42$ \\
\hline Cure Rate & $10(31.32)$ & $22(68.75)$ & $32(30.47)$ \\
\hline Boys & $7(70)$ & $8(36.36)$ & $15(46.87)$ \\
\hline Girls & $3(30)$ & $12(54.54)$ & $17(53.12)$ \\
\hline Recovery Rate & $15(57.69)$ & $11(42.30)$ & $26(24.76)$ \\
\hline Boys & $11(73.33)$ & $4(36.36)$ & $15(57.69)$ \\
\hline Girls & $4(26.66)$ & $7(63.63)$ & $11(42.30)$ \\
\hline Slow Responders & $17(94.44)$ & $1(5.56)$ & $18(17.14)$ \\
\hline Primary Failure & $12(63.15)$ & $7(36.84)$ & $19(18.09)$ \\
\hline Default & $5(62.5)$ & $3(37.5)$ & $8(7.6)$ \\
\hline Referred & - & $2(1.90)$ & $2(1.90)$ \\
\hline
\end{tabular}

\section{DISCUSSION}

Malnutrition in all its forms remains a major public health problem throughout the developing world. ${ }^{1,2}$ Our finding of SAM being more common than MAM is in consonance with a similar study conducted in India which reveals SAM among $61.9 \%$ and MAM among $30.09 \%$ of study population. ${ }^{15}$ The reason for the high incidence of SAM than MAM is unclear, but poor health seeking behavior during early stages of the condition due to lack of awareness about malnutrition in community especially in rural population could be the one. Besides in countries like ours parents generally do not seek medical advice for these malnourished children until unless they suffer from some acute complications. This is in contrast with finding in Ilam, eastern Nepal where MAM was more common than SAM(14\% vs $6 \%) .{ }^{16}$ This could be because it is a community based study, problems were picked up early.

Around $75(71.42 \%)$ children in study group were stunted with majority 51 (68\%) being severely stunted and 31(52.54\%) children had both severe wasting and severe stunting. This is almost double that of national level of stunting (36\%). ${ }^{1,4}$ Another study in Nepal showed slightly lower prevalence of both wasting and stunting (38.8\%). ${ }^{17}$ Similar trend was found by Chaudhary $\mathrm{M}$ et al in India where $40 \%$ patients were both severely wasted and stunted. ${ }^{18}$ Wasting and stunting probably share many causal pathways, and are unquestionably linked. Though the direct relationship between them has not been elaborated, one of the possibilities could be Leptin, a hormone secreted by fat which may have stimulating effect on immune system as well as on bone growth. This may explain why wasted children with low fat stores have reduced linear growth and frequent association of stunting with wasting.

Our finding suggestive of mostly affected age group being below 2 years of age, is in consistent with that found in India by Usha DR et al where $84.92 \%$ of children were in the age group $\leq 24$ months. ${ }^{15}$ Therefore, programs for children with malnutrition need to give priority to children younger than 2 years of age. Strikingly similar values have been reported in several other studies in India. ${ }^{11,18}$ In our study mean age of SAM as well as MAM were [mean \pm SD] $16.67 \pm 10.39$ months and $17.02 \pm 6.93$ months respectively, which agree with the finding in India. ${ }^{15}$ In the first 2 years of life, rapid growth occurs and requirement of substrates for energy and building of tissues also increases, thus deficiency of energy, protein and micronutrients often result in malnutrition. ${ }^{18}$ This is in contrast to the study in eastern Nepal where majority (56.45\%) were between 36-59 months, which could probably be because they did community based study covering larger population area and picking up the problem earlier. $^{16}$

Overall proportion of male and female children in this study was [1.14:1.], almost same as in study from India (1.15:1) and Ilam, Nepal. ${ }^{15,16}$ In our study boys were affected more with SAM and girls were affected more with MAM as was found in India revealing SAM among $57.7 \%$ boys and MAM among 58.3\% girls. ${ }^{15}$ Gunjan $\mathrm{T}$ et al and Singh $\mathrm{P}$ et al also found that boys were affected more with SAM, ${ }^{9,11}$ The causes of this apparent heightened vulnerability among boys needs further investigation, however it might be due to ritual and social norms, parents give more importance and seek medical advice more often for male child, though females are more likely to be malnourished than males and severity of malnutrition is also more in female children. ${ }^{18}$ Contrary to this girls were more severely malnourished than boys (84.2\% v/s 68.21\%) in Rajasthan. ${ }^{18}$

The progress of nutritional rehabilitation was assessed by the rate of weight gain expressed as gm/ $\mathrm{kg} /$ day. Our finding of average weight gain (gm/ $\mathrm{kg} /$ day) among total study population was similar to the finding Das Set al $6.99 \mathrm{gms}$ $/ \mathrm{kg} /$ day). ${ }^{19}$ However it is lower as compared to the finding of other similar studies in India. ${ }^{9,11,20}$ Besides only $15.23 \%$ at index rehabilitation center demonstrated the good weight gain(>8gm/Kg/Day) as compared to $30.9 \%$ in Bangladesh. ${ }^{21}$

There was not much difference in average weight again with respect to gender at index rehabilitation center however as compared to other studies in India it was less. ${ }^{9,20}$ Several factors could have resulted in this outcome. Key among them is the possible existence of co-morbidities prior to admission, inter-current infections due to poor immune status during the hospital stay, and lack of logistics and adequate human resource. Weight gain was better among the patients with SAM ( $6.99 \mathrm{gm} / \mathrm{kg} /$ day) than those with MAM (6.01 gm/kg/day) as was observed in Bangladesh. ${ }^{22}$ 
Although there was a difference between the mean weight at discharge $(7.28 \mathrm{~kg})$ and admission $(6.42 \mathrm{~kg})$ for the entire study group it was not as significant as shown in India., Cure rate $(30.47 \%)$ in our study was much below the recommended national and international level $(>75 \%) .{ }^{21}$ The proportion of children who achieved the target weight at the time of discharge was higher among children with MAM (68.75\%) than those with SAM (31.32\%). Cure rate in our study was higher in females which is in contrast to the finding in Bangladesh where overall cure rate was better among males (67.3\%) than female (56.8\%) children. ${ }^{22}$ Similar low and unacceptable cure rate was observed by Singh Pet al (47.2\%) and Das S et al (57.4\%) in the Nutrition Rehabilitation Centre (NRC) of India. Several factors could be behind this poor outcome in index study, most important one being early discharge seeking behavior. Because the mother had to stay with child for quite a long period at rehabilitation center, early discharge before reaching target weight was needed due to family burden, social issues and fund shortage. Many children were discharged after achieving a consistent pattern of satisfactory range of weight gain (5-10 $\mathrm{g} / \mathrm{kg}$ body weight/d) for 3 consecutive days. ${ }^{23}$ Some of these were said to be recovered as they attained WHZ >-2SD and were candidate for community level therapeutic care. Recovery rate was low $(24.76 \%)$ in our study, majority of them being male (54.54\%) and severely malnourished (57.69\%). Contrary to this, recovery rate among children with SAM in Srilanka is $93.9 \%$ which is because their cut off point for recovery was $\mathrm{WHZ}>-3 .^{13}$ This is a significant pointer to the high prevalence of malnutrition in children, particularly in peripheral locales, and argues in favor of community level rehabilitation.

Unlike the high prevalence of defaulter in India $(36.2 \%)^{19}$ and Bangladesh (19.3\%) ${ }^{21}$ the defaulter rate in our study $(7.6 \%)$ is within the acceptable levels of care $(<15 \%)$ mentioned in Sphere standard. ${ }^{21}$ Default rate was equal among male and female in our rehabilitation center whereas in Bangladesh it was higher among female than male (27.3\% vs $16.1 \%$ ) children. ${ }^{22}$ Primary failure rate $(18.09 \%)$ at our center was slightly higher than reported by at district level NRC(13.7\%) in India. ${ }^{12}$ Two cases (1.9\%) with MAM were referred for associated severe morbidity. A number of reasons could force care givers to take such drastic decision of defaulter and premature discharge such as; feeling well enough, personal and family problems, and general dissatisfaction with hospital referred to. Besides factors such as ignorance, poverty and of course in most developing countries, deeply rooted superstition among the care givers may attribute the cause of sicknesses to witchcraft and may forcefully seek discharge to consult spiritualists.
Average duration of stay $21.84 \pm 10.11$ days for entire study population, similar to the finding of Das $S$, which is within the acceptable international standard of $<8$ weeks. ${ }^{19,21}$ The short duration of stay not only decreases chances of cross exposure to infection and costs but also minimizes the absence of mothers from their homes which has got important social impact in this part of the world.

\section{CONCLUSION}

This study concludes that malnutrition is common among the children below 2 years of age. Severe acute malnutrition is more common as compared to moderate acute malnutrition and majority of malnourished children were severely stunted. As majority of admitted children had moderate weight gain, dietary interventions using locally available and affordable food stuff is found satisfactory in enhancing a child's nutritional status.

\section{RECOMMENDATIONS}

Management of SAM should not be a stand-alone program. It should integrate with community management therapeutic programs, and linkages with child treatment center, district hospitals and tertiary level centers offering inpatient management for malnutrition. Educational and sensitization programs and the introduction of supplementary and complementary feeding until the age of 2 years will be critical in curbing child malnutrition since majority of malnourished children were below 2 years of age.

\section{LIMITATIONS OF THE STUDY}

Limitation of our study was not having follow up, the eventual outcome of this group of children remain unknown which could have created a potential bias in presenting overall outcomes of the program. Besides the findings being area specific, generalization of the results with the whole country population could not be done.

\section{ACKNOWLEDGMENTS}

Dr Janardan Panthi, Medical Superintendent of Rapti SubRegional Hospital, Ghorahi Dang for administrative support and permission to carry out this study. Mrs Laxmi Gaire, Chief of Nutritional Rehabilitation Home Dang and all other nurses for preserving and providing the required data records.

\section{CONFLICT OF INTEREST}

None

\section{FINANCIAL DISCLOSURE}

None 


\section{REFERENCES}

1. UNICEF. The Burden Of Manutrition. Global Nutrtion Report 2018. 2018; Chapter 2:29-51.[URL]

2. Collins S. Treating severe acute malnutrition seriously. Arch Diseases of Childhood 2007; 97:453-461.DIO: 10.1136/adc.2006.098327 [DOI]

3. UNICEF, WHO, World Bank Group. UNICEF/WHO/WorldBank Group Joint child malnutrition estimates - levels and trends in child malnutrition Estimates WHO publication on Nutrition. 2019. [URL]

4. Ministry of Health (MOH) [Nepal], NewERA, and ICF International Calverton, Maryland. Nepal Demographic and Health Survey 2016. . Chapter11, Nutrition of Children and Adults 2017, November: 223. [URL]

5. WHO, UNICEF. WHO child growth standards and the identification of severe acute malnutrition in infants and children- A Joint Statement by the World Health Organization and the United Nations Children's Fund WHO publication on Nutrition. 2009:1-11.[URL]

6. Trehan I, Banerjee S, Murray E, Ryan K, Thakwalakwa C, Maleta K, Manary M. Extending Supplementary Feeding for Children Younger Than 5 Years With Moderate Acute Malnutrition Leads to Lower Relapse Rates Journal of Pediatric Gastroenterology and Nutrition. April 2015;60(4):544-549.DOI: 10.1097/MPG.0000000000000639 [DOI]

7. Briend A, Khara T, Dolan C. Wasting and Stunting-Similarities and Differences: Policy and Programmatic Implications. Food and Nutrition Bulletin. March 2015;36(1):15-23.DOI: 10.1177/ 15648265150361S103[DOI]

8. UNICEF. NEPAL Integrated Management of Acute Malnutrition (IMAM) Guideline Draft 7. Child Health Division, Ministry of Health and Population, Government of Nepal.; 2016.[URL]

9. Taneja G, Dixit S, Khatri AK, Yesikar V, Raghunath D, Chourasiya S. A Study to Evaluate the Effect of Nutritional Intervention Measures on Admitted Children in Selected Nutrition Rehabilitation Centers of Indore and Ujjain Divisions of the State of Madhya Pradesh (India). Indian Journal of Community Medicine. April 2012;37(2):107115. DOI:10.4103/0970-02 18.96096[DOI]

10. Saaka M, Osman SM, Amponsem A, Ziem JB, Mumin AA, Akanbong P, Yirkyio E, Yakubu E,and Ervin S. Treatment Outcome of Severe Acute Malnutrition Cases at the Tamale Teaching Hospital. Journal of Nutrition and Metabolism. 2015; Volume 2015,(Article ID 641784,):8 pages. DOI:10.1155/2015/641784[DOI]

11. Singh P, Kumar P, RohatgiS, Basu S, Aneja S. Experience and Outcome of Children with Severe Acute Malnutrition Using Locally Prepared Therapeutic Diet. Indian J Pediatr January 2016;83(1):3-8.DOI: 10.1007/s12098-015-1818-z[DOI|URL]

12. Dasgupta R, Ahuja S, Yumnam V. Can Nutrition Rehabilitation Centers Address Severe Malnutrition in India? Indian Pediatrics. February, 2014;51(2):95-99.[URL]
13. Jayatissa R, Bekele A, Kethiswaran A, De Silva A.H. Community-Based Management of Severe and Moderate Acute Malnutrition during Emergencies in Sri Lanka: Challenges of Implementation. Food and Nutrition Bulletin. 2012; 33(4):251-260.DOI:10.1177\%2F1564826 51203300405[DOI]

14. UNICEF. NEPAL Integrated Management of Acute Malnutrition (IMAM) Guideline Draft 7. Vol Annex 20.: Child Health Division, Ministry of Health and Population, Government of Nepal; 2016:44.

15. Usha DR, Krishmamurthy S, Bhat BV, Sahai A. Epidemiological and Clinical Profile of Hospitalized Children with Moderate and Severe Acute Malnutrition in South India. Indian J Pediatr. June 2015;82(6):504-510.DOI 10.1007/s12098-014-1671-5[DOI]

16. Niraula SR, Barnwal SP, PaudelS, MishraS, DahalS, Das2, PradhanS, GhimireS, SKhanalS, SharmaS, RajputS, BhattaraiS, Jha N. Prevalence and associated risk factors with malnutrition among under- five Nepalese children of Borbote village, Ilam. Health Renaissance 2013;11(2):111118. DOI: 10.3126/hren.v11i2.8217[DOI]

17. Thapa A, Shah GS, Mishra OP. Analysis of Co-morbidities in Children with Severe Acute Malnutrition in Eastern Nepal. J. Nepal Paediatr. Soc. May-August, 2015; 35(2):99-102.DOI:10.3126/jnps.v35i2. 13098[DOI]

18. Choudhary M, Sharma D, Nagar RP, Gupta BD , Nagar T, Pandita A. Clinical Profile of Severe Acute Malnutrition in Western Rajasthan: A Prospective Observational Study from India. Journal of Pediatrics and Neonatal Care. 2015;2(1):00057.DOI:10.15406/jnmr.2015.02.00057[DOI]

19. Das S, Paul DK, Bhattacharya M, Basu S, Chatterjee A, Sen S, Bhakta S. Clinicoepidemiological Profile, Risk Factors and Outcome of Severe Acute Malnutrition Children at the Nutritional Rehabilitation Centre of a Tertiary Care Centre in Eastern India- A 4 Years Experience. Adv Res Gastroenterology and Hepatology. May 2017;5(2):1-8.DOI: 10.19080/ARGH.2017.05.555659[DOI]

20. Panda PC, Soren G, Rout S, Behera R. Outcome of Severe Acute Malnutrition Management at a Tertiary Care Nutrition Rehabilitation Centre. Journal of Medical Science and Clinical Research. April 2019;7 (4):112-124.DOI: $10.18535 / \mathrm{jmscr} / \mathrm{v7i4}$.22[DOI]

21. Hossain MI, Dodd NS, Ahmed T, Miah GM, Jamil KM, Nahar B et al. Experience in Managing Severe Malnutrition in a Government Tertiary Treatment Facility in Bangladesh. J Health Population and Nutrition. 2009;27(1):72-79.[URL]

22. Ahmed AU, Ahmed TU, Uddin S, Choudhary AH, Rahaman MH, Hossain I. Outcome of Standardized Case Management of Under-5 Children with Severe Acute Malnutrition in Three Hospitals of Dhaka City in Bangladesh. BANGLADESH J CHILD HEALTH 2013; VOL 37 (1) : 513. 2013;37(1):5-13.DOI: 10.3329/bjch.v37i1.15345[DOI]

23. Ashworth A, Khanum S, Jackson A, Schofield C. Guidelines for the Inpatient Treatment of Severely Malnourished Children. New Delhi: South-East Asian Regional Office,World Health Organization.; 2003. [URL] 